\section{Overview of pelvic floor failure and associated problems}

\author{
Khaled Refaat, ${ }^{1}$ \\ Constanze Fischer-Hammadeh, ${ }^{2}$ \\ Mohamad Eid Hammadeh ${ }^{2}$
}

'Department of Obstetrics \& Gynecology, Al Azhar University, Egypt; ${ }^{2}$ Department of Obstetrics and Gynecology, University of Saarland, Homburg-Saar, Germany

\section{Abstract}

Pelvic organ prolapse POP, including anterior and posterior vaginal prolapse, uterine prolapse, and enterocele, is a common group of clinical conditions affecting millions of women worldwide. The aim of this review is to highlight the clinical importance of prolapse, its pathophysiology, and different modalities for diagnosis and treatment. POP includes a range of disorders, from asymptomatic disturbed vaginal anatomy to complete vaginal eversion associated with considerable degrees of urinary, defecatory, and sexual dysfunction. The pathophysiology of prolapse is multifactorial however genetically susceptible women are more exposed to life events that result in the development of clinically significant prolapse. The evaluation of women with prolapse requires a comprehensive approach, with focusing on the function in all pelvic compartments based on a detailed patient history, physical examination, and investigations. Although prolapse is associated with many symptoms, few are specific for prolapse; it is often a challenge for the clinician to determine which symptoms are prolapse-specific and will therefore improve or resolve after prolapse treatment. Prolapse treatment is based on specific symptoms moreover its management options fall into two broad categories: nonsurgical, which includes pelvic floor muscle training and pessary use; and surgical, which can be reconstructive or obliterative. Associated symptoms require additional management. All women with prolapse can be treated and their symptoms improved, even if not completely resolved.

\section{Introduction}

Pelvic organ prolapse (POP) is a bulge or protrusion of pelvic organs and their associated vaginal segments into or through the vagina. ${ }^{1}$ It commonly affects older women. A North American analysis revealed that a woman up to the age of 80 years has an $11 \%$ risk of needing surgery for pelvic floor weakness. Furthermore, if she has an operation, she has a $29 \%$ risk of requiring further surgery. ${ }^{2}$ It has been thought that over the next 30 years, the demand for treatment of POP will increase $45 \%$, matching with an increase in the number of women above 50 years old. ${ }^{3}$ It is estimated that up to half of the normal female population will develop uterovaginal prolapse during their lifetime. Twenty percent of these women will be symptomatic and need treatment. ${ }^{4}$

As this problem grows significantly, it becomes important to focus on understanding of the pathophysiology and risk factors associated with pelvic organ prolapse to try to prevent its occurrence. Furthermore, more efforts are needed to understand factors that result in long-lasting, effective repair of pelvic organ prolapse for those patients undergoing surgical management. Despite extensive experience, the optimal surgical approach to apical and other compartment prolapse remains a matter of debate. ${ }^{5}$

Data from the Women's Health Initiative revealed anterior pelvic organ prolapse in $34.3 \%$, posterior wall prolapse in $18.6 \%$, and uterine prolapse in $14.3 \%$ of women in the study. ${ }^{6}$

In this study, a significant risk factor associated with prolapse was vaginal delivery. After adjusting for age, ethnicity, and body mass index, women with at least one vaginal delivery were twice as likely as nulliparous women to have pelvic organ prolapse. Causes of POP are most likely multifactorial, however; factors other than vaginal delivery also are associated with the development of these disorders. Gurel et al., found that the incidence of prolapse doubled with each decade of life between the ages of 20 and 59 years. ${ }^{7}$

In another study, each year of increasing age was associated with a $12 \%$ increase in the risk of developing prolapse. ${ }^{8}$ Other associated risk factors for the development of POP include history of hysterectomy, ${ }^{7}$ obesity, ${ }^{9}$ history of previous prolapse operations, and race. ${ }^{10}$

\section{Pathophysiology}

The main cause of pelvic organ prolapse is the attenuation of the supportive structures, whether by actual tears or "breaks" or by neuromuscular dysfunction or both. The vagina is supported by the enveloping endopelvic connective tissue and its condensations at the vaginal apex, which form the cardinal uterosacral ligament complex. The endopelvic connective tissue is the first line of support. The second line is the pelvic diaphragm, composed of the levator ani and coccygeus muscles. These muscles provide a supportive diaphragm through which the urethra, vagina, and rectum pass.
Correspondence: M.E. Hammadeh, Department of Obstetrics and Gynecology, University of Saarland, Homburg-Saar, Germany. Tel. +4968411628117 - Fax: +4968411628061

E-mail: mehammadeh@yahoo.de

Key words: pelvic organ prolapse; urinary incontinence; sexual problems.

Received for publication: 29 September 2011.

Revision received: 27 October 2011.

Accepted for publication: 28 November 2011.

This work is licensed under a Creative Commons Attribution NonCommercial 3.0 License (CC BYNC 3.0).

(C) Copyright K.R. Refaat et al., 2012

Licensee PAGEPress, Italy

Urogynaecologia 2012; $26: e 2$

doi:10.4081/uij.2012.e2

\section{Muscle}

The striated muscle of the pelvic floor, in common with other striated muscles throughout the body, undergoes a gradual denervation with age. ${ }^{11}$

This denervation will lead to a gradual weakening of the muscle with time. While some of the aging effect can be compensated for by muscle training, the impact of denervation will be to diminish the number of neurones which can stimulate muscle fibres to contract. Pelvic floor muscle denervation is increased by repeated vaginal delivery, particularly in case of prolonged second stage of labour. ${ }^{12}$

\section{Fascia}

Recently, our understanding of the frequency of fascial tears has improved with intraoperative dissection. Careful examination of prolapse segments as well as careful dissection of the fibromuscular layer from the overlying vaginal epithelium frequently identifies specific tears in this fibromuscular layer. It has become clear that fascial tears tend to begin as apical transverse defects, or separation of the fibromuscular layer from the vaginal apex or cervix, with the highest degree of frequency. Recent studies reveal that the highest incidence of fascial separation occurs as superior transverse fascial defects posteriorly. This will typically lead to the formation of what is commonly thought of as an enterocele. ${ }^{13}$

Restoration of attachment of this layer to the vaginal apex will also reduce an obvious rectocele very often. Thus, restoration of intact attachment of the fibromuscular layer to the vaginal cuff can be an important part of the correction of any posterior vaginal prolapse. Along the anterior vaginal wall, superior transverse fibromuscular layer separation is also very common in the development of a cysto- 
cele, and may be more clinically significant than paravaginal separation. ${ }^{14}$

\section{Classification}

Prolapse is normally divided into anterior, uterine/vault and posterior compartments. Although anterior vaginal wall prolapse is still commonly called a cystocoele and posterior prolapse a rectocoele or enterocoele the difficulty in providing reproducible descriptions for the purpose of research has led to the development of scoring systems. The most frequently used validated method in current literature is a system called the Pelvic Organ Prolapse Quantification (POPQ). ${ }^{15}$ The system is shown diagrammatically in Figure 1.

The POPQ is a valid system for staging for vaginal prolapse. This staging system separately addresses the vaginal compartments (anterior, posterior, apical) and defines the extent of prolapse in relation to the hymen. Stage 0 indicates no prolapse, stage 1 implies that the most distal portion of the prolapsed organ is $0.1 \mathrm{~cm}$ above the hymenal ring, stage 2 defines prolapse within $1 \mathrm{~cm}$ of the hymen (proximal or distal), stage 3 denotes prolapse $0.1 \mathrm{~cm}$ distal to the hymen, and stage 4 implies complete vaginal eversion. ${ }^{15}$

According to a dynamic pelvic magnetic resonance imaging (MRI) for patients with uterine prolapse, Prolapse is classified in reference to the puborectalis hiatus (sling), which is formed by the puborectalis muscle (the most inferior part of levator ani) and includes the urethra, vagina, and rectum. The degree of prolapse is based on 2-cm increments: mild uterine prolapse is between 0 and $2 \mathrm{~cm}$ below the hiatus, moderate prolapse is $2-4 \mathrm{~cm}$, and severe prolapse is $0.4 \mathrm{~cm}$ below the hiatus. ${ }^{16}$

\section{Clinical presentation}

POP and symptoms of pelvic organ dysfunction are both common in the general population and may occur concurrently, but independently. It is important to understand the correlation between patients' symptoms and clinical staging of POP. Many studies have reported little or no agreement between POP severity and symptoms of bladder and bowel dysfunction. ${ }^{17-19}$

The most reliable symptom, which has previously shown to be well related to the severity of prolapse, was to see or to feel a bulge in the vagina..$^{20-21}$

\section{Mechanical symptoms}

Three studies showed quite consistent rates of mechanical symptoms of around $8 \%$ among older women..$^{22-24}$ Mechanical symptoms are often presented when the prominent edge of the prolapse is at or outside the hymen..$^{25}$
Prolapse classically produces a sensation of fullness in the vagina or a visible or palpable lump at the introitus. This sensation is always related to posture. If the symptoms do not resolve when lying down an alternative aetiology should be considered. Low backache is a common symptom but is also commonly experienced by women who do not have prolapse. Vaginal atrophy, if present, will exacerbate many prolapse symptoms and should be treated as a first priority with topical oestrogens unless clinically contraindicated.

\section{Lower urinary tract symptoms}

POP is often associated with incontinence and voiding problems. ${ }^{26-28}$ Severe stages of anterior wall prolapse correlate with voiding problems with the need to manually reduce the prolapse to urinate..$^{29,30}$

A more vague feeling of bladder-emptying problems may be reported by $30-50 \%$ of patients without specific relation to the prolapsed compartment. Some recent studies showed that $13-83 \%$ of patients with POP also complained of stress incontinence, and $21-73 \%$ of urge incontinence. ${ }^{26,28}$ In population studies, $15-20 \%$ of women in this age group complain of incontinence. ${ }^{31}$

POP is usually associated with incontinence regardless the presence of a strict relation to the prolapsed compartment or not. There is a tendency for urge incontinence (UI) to improve with more severe POP stages, while voiding problems are aggravated. Repair of prolapse can improve or cure both voiding problems and stress and urge incontinence in more than half of the cases. ${ }^{30,32}$

It is highly recommended to perform urodynamics, Q-tip test, fluoroscopy, ultrasonograhy, and reduction of the prolapse with pessary and speculum tests in order to evaluate coexisting or occult incontinence in women with prolapse. ${ }^{33-36}$

Masked incontinence may be revealed, after correction of urethral kinking and compression by reduction of the prolapse, and is reported in $15-22 \%$ of patients. ${ }^{37,38}$ In many studies, the consequence of a demasking test was taken, and the expected incontinence operated in the same session with POP surgery without validating the efficacy of the test. Weil et al., showed that the pessary test was falsely positive in $72 \%$ and falsely negative in $10 \%$ of 40 patients. Urodynamic tests with and without prolapse reduction cannot determine the outcome of overactive detrusor function. Also the efficacy of the anti-incontinence surgery, done simultaneous by vaginal repair, cannot be predicted by these tests. ${ }^{32,39}$

\section{Bowel symptoms}

Posterior vaginal wall prolapse may be presented with a range of bowel symptoms.

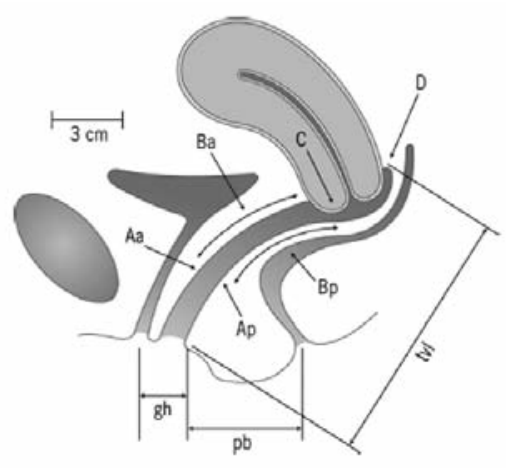

Figure 1. Pelvic Organ Prolapse Quantification system. (Abbreviations: Aa, anterior wall; Ap, posterior wall; $\mathrm{Ba}$, anterior wall; $\mathrm{Bp}$, posterior wall; $\mathrm{C}$, cervix or cuff; D,posterior fornix; gh, genital hiatus; $\mathrm{pb}$, perineal body; tvl, total vaginal length). Modified from Bump RC, Mattiasson A, Bo K, et al. ${ }^{15}$

Constipation is a common symptom in women and may contribute to obstructed defecation. The presence of posterior vaginal wall prolapse may not be the cause of the obstructed defaecation but more a symptom of it. Posterior vaginal wall prolapse does not normally result in ano-rectal incontinence. ${ }^{40}$

\section{Sexual dysfunction}

Treatment of POP and UI usually concentrate more on anatomy and cure of UI than sexual dysfunction. Many studies are retrospective $\mathrm{e}^{41-42}$ and based mainly on dyspareunia and general sexual wellbeing as the key aspects of female sexual function. Dyspareunia is a multifactorial and common symptom among older women, often due to vaginal dryness, atrophy, low oestrogen levels, and old age. .1-43 $^{4}$

The frequency of sexual activity did not differ in a group with UI or POP compared to controls. Decreased sexual satisfaction because of urine leakage during intercourse, embarrassment, dyspareunia, and vaginal dryness were significantly more common in the group with UI or POP compared to controls. ${ }^{44}$ In another study, it has been shown that most sexual problems were in the group with UI and were associated with decreased libido, vaginal dryness and dyspareunia, while POP was not associated with sexual problems in this stud. ${ }^{45}$

The relation of sexual function to cure of UI and objective vaginal dimensions before and after treatment for POP is weak. ${ }^{20,42}$ Deterioration of emotional status of sexual life in spite of physical improvement after POP and UI surgery was found in a study using PISQ-12, which is a specific questionnaire in both a long- and a short-form with 12 questions covers broader aspects of female sex life, and has been validated for use in patients with pelvic floor dysfunction. ${ }^{46}$

The sexual outcome was not related to age, 
type of surgery, oestrogen status, and cure or not of incontinence symptoms. Other studies showed that vaginal surgeries, especially posterior colporrhaphy, vaginal atrophy, old age and partner's medical and sexual problems, are considered risk factors for sexual dysfunction and dyspareunia in women. ${ }^{39,41,42}$

Sexual complaints in women can be related to many physical problems: e.g. urine leakage during intercourse, dyspareunia from the feeling of a narrow or short vagina, vaginal dryness, scar tissue and mucosal bridges from prior vaginal tears or surgery, and/or due to emotional impact of menopause, pelvic floor dysfunction, and partner relationship and function. Clinicians need more information in order to assess these factors to be able to counsel patients and adjust surgical techniques.

\section{Physical assessment}

It is useful to divide the pelvis into compartments, each of which may exhibit specific defects. The apical compartment of the vagina can be assessed by the use of a Graves speculum or Baden retractor. The anterior and posterior compartments are best examined with the use of Sims' speculum. The speculum is placed posteriorly to retract the posterior wall downward when examining the anterior compartment and placed anteriorly to retract the anterior wall upward when examining the posterior compartment. A rectovaginal examination is helpful in evaluating the posterior compartment to differentiate between a posterior vaginal wall defect and a dissecting apical enterocele or a combination of both. During the evaluation of each compartment, the patient is encouraged to perform Valsalva so the full extent of the prolapse can be assessed. If the findings determined with Valsalva are not correlated with the patient's description of her symptoms, it may be helpful to perform a standing straining examination with the bladder empty. ${ }^{47}$

\section{Imaging}

Imaging studies including ultrasonography, computed tomography (CT) scan, and MRI are useful in the determination of POP. The CT scan and sector, real-time, or three-dimensional ultrasonography have been employed to provide anatomic details of the pelvic floor support. MRI is an emerging technique for the study of pelvic floor dysfunction and holds promise due to its excellent ability to differentiate soft tissues. ${ }^{48}$

However, their use is currently limited to research rather than clinical practice due to the cost and lack of standardized criteria for the diagnosis of POP. It is also important to take into account the quality of life in women with pelvic floor disorders when planning treatment and evaluating the efficacy of a particular therapy. ${ }^{21,49}$

\section{Cystography}

Lateral cystography provides a static view of the bladder and bladder outlet in relation to the pubic bony structures. Early investigators used a bead chain cystourethrogram to aid with the analysis of the posterior urethrovesical angle. ${ }^{50}$

\section{Ultrasound}

Sonography is considered a convenient, inexpensive, and radiation-free technique. The integrity of the anal sphincter muscles can be assessed with a high-frequency ( $7 \mathrm{MHz}$ ) transducer that produces a panoramic image. ${ }^{51}$ The internal sphincter defects generally appear as an echogenic discontinuity in the hypoechoic muscle between the vagina and rectum. On the other hand, external sphincteric injuries appear as hypoechoic lesions in a normally echogenic structure. ${ }^{51}$ Sonographic findings predict intraoperative diagnosis with a 95\% accuracy. ${ }^{52,53}$ The recent advent of 3D sonography may further increase our understanding of anal sphincteric dysfunction. ${ }^{54}$

\section{Computed tomography}

Computerized axial tomography (CT) has not been shown to be particularly useful in the evaluation of pelvic organ prolapse. This radiological method has the disadvantage of imaging structures, which lie in the axial plane via an axial imaging technique. ${ }^{55}$

\section{Magnetic resonance imaging}

The fast-scanning MRI technique has a great value in describing and quantifying anatomical changes that may cause pelvic floor relaxation. MRI can be used to evaluate the female pelvis without ionizing radiation. Organ descent may be simultaneously assessed in all three pelvic compartments. ${ }^{56}$

Additionally, MRI has been shown to have a useful role in measuring levator muscle thickness, ${ }^{57}$ urethral length, and the thickness and integrity of periurethral muscle ring. ${ }^{58}$ The addition of 3D imaging has the advantage of quantification of muscle volume, which may give a more accurate representation of the relationships among pelvic floor structures, thereby potentially improving surgical planning. ${ }^{57}$

\section{Treatment}

\section{Nonsurgical therapy}

Nonsurgical therapy of pelvic organ prolapse includes conservative behavioral management and the use of mechanical devices. A nonsurgical treatment approach usually is considered in women with mild to moderate prolapse, those who desire preservation of future childbearing, those in whom surgery may not be an option, or those who do not desire surgical intervention.

\section{Conservative management}

Conservative management approaches include alteration of lifestyle or physical activities such as pelvic floor muscle training (PFMT). These lines of treatment are used mainly in cases of mild to moderate prolapse; however, their actual role in managing prolapse and associated symptoms is uncertain. ${ }^{59,60}$ Lifestyle intervention includes carrying out activities that reduce weight and avoiding of those activities that increase intraabdominal pressure. Pelvic floor muscle exercises may decrease the progression of mild prolapse and related symptoms; ${ }^{61,62}$ however, a lower response rate has been observed when prolapse extends beyond the vaginal introitus. ${ }^{63}$ The efficacy of biofeedback therapy in the treatment of impaired defecation associated with a rectocele has been determined. ${ }^{64}$

\section{Mechanical devices}

The use of mechanical devices such as pessaries is usually considered in women who cannot undergo surgery for medical reasons, desire to avoid surgery, or have a significant degree of prolapse that makes other nonsurgical approaches unfeasible. Indications extended to include pregnancy-related prolapse as well as prolapse and incontinence in elderly women. Reports have shown that age older than 65 years, the presence of severe medical comorbidity, ${ }^{65}$ and sexual activity ${ }^{66}$ were associated with successful pessary user.

There are no randomized controlled trials of pessary use in women with POP. ${ }^{67}$ Moreover, there are no consensus guidelines on the care of pessaries (i.e., intervals between changes), the role of local estrogens, or the type of pessary indicated for specific types of POP. ${ }^{67}$

Effective outcomes have been reported for stage II or greater prolapse using the Gelhorn and ring diaphragm pessary. ${ }^{65}$ After 2 to 6 months, $77 \%$ to $92 \%$ of women with a successful pessary fitting were satisfied.

Possible complications associated with pessary use include vaginal discharge and infection. Failure to retain the pessary may occur or on the other side, the pessary may be too large, which could result in excoriation or irritation. With reduction of vaginal prolapse, de novo or increased stress incontinence may occur, ${ }^{68}$ and in rare cases, more severe complications, including vesicovaginal fistula, small bowel entrapment, and hydronephrosis have been described. ${ }^{69,70}$ 


\section{Surgical management}

The primary aim of surgery is to relieve or improve prolapse symptoms and, if possible, symptoms associated with the lower urinary and gastrointestinal tracts. In some women, this means an attempt to restore normal vaginal anatomy and maintain or improve sexual function. In others, an obliterative approach is more appropriate and still yields the desired result of symptom relief.

\section{Approach}

Prolapse surgery approaches include vaginal, abdominal, and laparoscopic routes or a combination of approaches. ${ }^{71-73}$ Depending on the degree and location of prolapse, surgery usually involves a combination of repairs addressing the anterior vaginal wall, vaginal apex, posterior vaginal wall, and perineum; concomitant surgery may be needed for the bladder neck or anal sphincters. Procedures for posterior vaginal prolapse most commonly use a transvaginal approach, or less commonly, a transanal approach. Apical and anterior vaginal prolapse can be approached by either vaginal or abdominal routes. It is beneficial to compare the vaginal approach with the abdominal approach (i.e., laparotomy), from the perspective of complications and short-term effects on recovery. The vaginal approach has fewer wound complications, less postoperative pain, shorter hospital stay, and less cost than abdominal surgery. ${ }^{71,72}$

\section{Anterior vaginal repair}

Anterior vaginal prolapse has traditionally been repaired with anterior colporrhaphy, where the vaginal epithelium is separated from the underlying fibromuscular connective tissue, followed by midline placation of the vaginal muscularis with a series of interrupted stitches, usually of absorbable suture, excision of excess epithelium, and closure. ${ }^{14}$

Variations in this technique include placing graft material on top of or instead of the midline plication. There are two randomized trials showed that a considerable improvement in success was noticed, adding $12-18 \%$ to the cure rates after 1 year, when polyglactin mesh (Vicryl; Ethicon, Somerville, NJ, USA) was placed over the midline plication compared with standard repair. ${ }^{74,75}$

\section{Posterior vaginal repair}

The basic technique used for treatment of posterior vaginal wall prolapse is posterior colporrhaphy. This technique involves separation of the vaginal epithelium from the underlying fibromuscular connective tissue (which includes the rectovaginal septum, followed by midline plication with interrupted stitches, excision of excess epithelium, and closure. Variations also include placing graft material on top of or instead of the midline plication. Other procedures can be combined with posterior colporrhaphy, such as levator ani plication and perineorrhaphy, however the indications for these additions are controversial. ${ }^{76}$

Dyspareunia is reported as a complication of this procedure due to levator ani plication if a band or narrowing is formed inside the vagina. ${ }^{54}$ Narrowing can also occur with marked perineorrhaphy or combinations of procedures that change normal vaginal contours. Dyspareunia is more liable to occur when Burch is performed with posterior repair, when the altered vaginal contour and posterior transverse ridge is overlaid with the plication of the posterior repair. After posterior repair, there should be a careful attention to ensure adequate introital caliber. Despite the previous precaution, $38 \%$ of women after Burch and posterior repair had persistent dyspareunia 1 year or more after surgery. ${ }^{39}$

\section{Vaginal apical repair}

Apical vaginal prolapse includes uterine prolapse with or without enterocele and vaginal vault prolapse, typically with enterocele. Uterine prolapse may be presented in some cases with marked elongation of the cervix. The standard management for symptomatic uterine prolapse is hysterectomy with additional procedures to suspend the vaginal apex, correct enterocele when indicated, repair associated anterior and posterior vaginal prolapse, and perform antiincontinence procedures as required. It is particularly important to perform a specific vaginal vault suspension procedure in addition to hysterectomy because when hysterectomy is performed for prolapse, hysterectomy alone (or hysterectomy with colporrhaphy) is inadequate.

\section{Enterocele repair}

Enterocele repair is usually performed in association of concomitant prolapse procedures, in which case the approach is based on the combination of procedures required. Whether by vaginal, abdominal, or laparoscopic access, enterocele repair is basically done by sharply dissecting the peritoneal sac from the rectum and bladder. A purse-string suture is performed to close the peritoneum as high as possible. In addition to obliterating the enterocele sac, it is recommended to approximate the anterior to the posterior fibromuscular connective tissue of the vagina. Suspension of the vaginal apex is essential, except in rare cases when the enterocele occurs in the presence of adequate apical support. ${ }^{77}$

\section{Post-hysterectomy (apical) vaginal prolapse}

Post-hysterectomy (apical) vaginal prolapse is defined as descent of the vaginal cuff scar below a point that is $2 \mathrm{~cm}$ less than the total vaginal length above the plane of the hymen. ${ }^{78}$ The vaginal cuff scar corresponds to point $\mathrm{C}$ on the POPQ grid. ${ }^{15}$

A number of definitions have been used in studies carried out prior to the introduction of standard terminology by the International Continence Society. ${ }^{1}$ A retrospective follow up of 448 women undergoing hysterectomy, using the definition described by Baden et al., ${ }^{79}$ showed the condition to follow $11.6 \%$ of hysterectomies performed for prolapse and $1.8 \%$ of those performed for other indications. ${ }^{80}$

Although several surgical procedures have been described, randomised controlled studies specifically addressing post-hysterectomy vaginal vault prolapse are limited and most reports are based on case series.

\section{Prevention at the time of hysterec- tomy}

A small-randomised trial compared vaginal Moschowitz-type operation, McCall's culdoplasty and peritoneal closure of the cul-de-sac as preventive measures against the development of enterocele. It included 100 women and showed that McCall's culdoplasty was more effective than vaginal Moschowitz or simple closure of the peritoneum in preventing enterocele at 3 years' follow-up. ${ }^{81}$

The technique involves approximating the uterosacral ligaments using continuous sutures, so as to obliterate the peritoneum of the posterior cul-de-sac as high as possible. ${ }^{82} \mathrm{~A}$ similar approach has been described for abdominal hysterectomy. ${ }^{83,84}$

Attaching the uterosacral and cardinal ligaments to the vaginal cuff and high circumferential obliteration of the pouch of Douglas has been suggested to prevent vault prolapse and enterocele formation. ${ }^{85}$ No cases of vault prolapse or enterocele were recorded among 112 patients over a follow-up period extending from 7 to 42 months.

Prophylactic sacrospinous fixation has been suggested at the time of vaginal hysterectomy for marked uterovaginal prolapse, ${ }^{81}$ when the vault (point $\mathrm{C}$ on the POPQ system) could be pulled to the introitus at the end of anterior vaginal wall closure, which is a selected subgroup of those undergoing vaginal hysterectomy. A retrospective study reported the outcome in 48 patients at a mean follow-up of 2 years. ${ }^{81}$

\section{Surgical repair of post-hysterecto- my (apical) vaginal prolapse}

Abdominal sacrocolpopexy is an effective operation for post-hysterectomy vaginal vault prolapse. In comparison, sacrospinous fixation may have a higher failure rate but has lower postoperative morbidity. Only one prospective randomised controlled study compared abdominal sacrocolpopexy and unilateral sacrospinous 
fixation for post-hysterectomy vaginal vault prolapse. This study was relatively small, including 89 women, and the follow-up duration ranged from 6 to 60 months. Additional prolapse and continence surgery was performed as required. Abdominal sacrocolpopexy was associated with significantly longer operating time, slower return to normal activity and higher cost. There was no significant difference in terms of objective and subjective success, urinary, bowel or sexual dysfunction or quality of life. ${ }^{86}$

\section{References}

1. American College of Obstetricians and Gynecologists. Pelvic organ prolapse. ACOG Technical Bulletin. Int J Gynaecol Obstet 1996;52:197-205.

2. Olsen AL, Smith VJ, Bergstrom J0, et al. Epidemiology of surgically managed pelvic organ prolapse and urinary incontinence. Obstet Gynecol 1997;89:501-6.

3. Luber KM, Boero S, Choe JY. The demographics of pelvic floor disorders: current observations and future projections. Am J Obstet Gynecol 2001;184:1496-501.

4. Beck RP, McCormick S \& Nordstrom L. A 25year experience with anterior colporrhaphy procedures. Obstet Gynecol 1991;78:1011-8.

5. Brubaker L. Controversies and uncertainties: abdominal versus vaginal surgery for pelvic organ prolapse. Am J Obstet Gynecol 2005;192:690-3.

6. Hendrix SL, Clark A, Nygaard I, et al. Pelvic organ prolapse in the Women's Health Initiative: gravity and gravidity. Am J Obstet Gynecol 2002;186:1160-6.

7. Gurel H, Gurel SA. Pelvic relaxation and associated risk factors: the results of logistic regression analysis. Acta Obstet Gynecol Scand 1999;78:290-3.

8. Swift SE, Pound T, Dias JK. Case-control study of etiologic factors in the development of severe pelvic organ prolapse. Int Urogynecol J Pelvic Floor Dysfunct 2001;12:187-92.

9. Fornell EU, Wingren G, Kjolhede P. Factors associated with pelvic floor dysfunction with emphasis on urinary and fecal incontinence and genital prolapse: an epidemiologic study. Acta Obstet Gynecol Scand 2004;83:383-9.

10. Moalli PA, Ivy SJ, Meyn LA, et al. Risk factors associated with pelvic floor disorders in women undergoing surgical repair. Obstet Gynecol 2003;101:869-874.

11. Smith AR, Hosker GL, Warrell DW.The role of partial denervation of the pelvic floor in the aetiology of genitourinary prolapse and stress incontinence of urine. A neurophysiological study. Br J Obstet Gynaecol 1989;96: 24-8.
12. Allen RE, Hosker GL, Smith AR, Warrell DW. Pelvic floor damage and childbirth: a neurophysiological study. Br J Obstet Gynaecol 1990;97:770-9.

13. Guerette N, Davila GW. Can discrete vaginal fascial defects be accurately identified preoperatively? Neurourol Urodyn 2004;23: 436-7.

14. Weber AM, Walters MD. Anterior vaginal prolapse: review of anatomy and techniques of surgical repair. Obstet Gynecol 1997;89: 331-8.

15. Bump RC, Hurt WG, Theofrastous JP, et al. Randomized prospective comparison of needle colposuspension versus endopelvic fascia plication for potential stress incontinence prophylaxis in women undergoing vaginal reconstruction for stage III or IV pelvic organ prolapse. The Continence Program for Women Research Group. Am J Obstet Gynecol 1996;175:326-33; discussion 333-5.

16. Barbaric ZL, Marumoto AK, Raz S. Magnetic resonance imaging of the perineum and pelvic floor. Top Magn Reson Imaging 2001;12:83-92.

17. Bradley CS, Nygaard IE. Vaginal wall descensus and pelvic floor symptoms in older women. Obstet Gynecol 2005;106: 75966.

18. Burrows LJ, Meyn LA, Walters MD, Weber AM. Pelvic symptoms in women with pelvic organ prolapse. Obstet Gynecol 2004;104:982-8.

19. Chou Q, Weber AM, Piedmonte MR. Clinical presentation of enterocele. Obstet Gynecol 2000;96:599-603.

20. Ellerkmann RM, Cundiff GW, Melick CF, et al. Correlation of symptoms with location and severity of pelvic organ prolapse. Am J Obstet Gynecol 2001;185:1332-7.

21. Barber MD, Neubauer NL, Klein-Olarte V. Can we screen for pelvic organ prolapse without a physical examination in epidemiologic studies? Am J Obstet Gynecol 2006;195:942-8.

22. Kumari S, Walia I, Singh A. Self-reported uterine prolapse in a resettlement colony of north India. J Midwifery Womens Health 2000;45:343-50.

23. MacLennan AH, Taylor AW, Wilson DH, Wilson D. The prevalence of pelvic floor disorders and their relationship to gender, age, parity and mode of delivery. Br J Obstet Gynecol 2000;107:1460-70.

24. Tegerstedt G, Miedel A, Maehle-Schmidt M, et al. A short-form questionnaire for identified genital organ prolapse. J Clin Epidemiol 2005;58:1-46.

25. Swift SE, Tate SB, Nicholas J. Correlation of symptoms with degree of pelvic organ prolapse in a general population of women: what is pelvic organ prolapse. Am J Obstet Gynecol 2003;189:272-9.
26. Mouritsen L, Prien-Larsen J. Symptoms, bother and $\mathrm{POPQ}$ in women referred with pelvic organ prolapse. Int Urogynecol $\mathbf{J}$ 2003;14:122-7.

27. Tan JS, Lukacz ES, Menefee SA, et al. Predictive value of prolapse symptoms: a large database study. Int Urogynecol J 2005;16:203-9.

28. Bai SW, Jeon JM, Kim JY, et al. Relationship between urinary incontinence and pelvic organ prolapse. Int Urogynecol J 2002;13:256-60.

29. Romanzi LJ, Chaikin DC, Blaivas JG. The effect of genital prolapse on voiding. J Urol 1999;161:581-6.

30. Gardy M, Kozminski M, DeLancey J, et al. Stress incontinence and cystoceles. J Urol 1991;145:1211-3.

31. Moller LA, Lose G, Jorgensen T. The prevalence and bothersomeness of lower urinary tract symptoms in women 40-60 years of age. Acta Obstet Gynecol Scand 2000;79:298305.

32. Nguyen J, Bhatia NN. Resolution in motor urge incontinence after surgical repair of pelvic organ prolapse. J Urol 2001;166:22636.

33. Cogan SL, Weber AM, Hammel JP. Is urethral mobility really being assessed by the pelvic organ prolapse quantification system (POPQ)? Obstet Gynecol 2002;99:473-6.

34. Kenton K, Shott S, Brubaker L. Vaginal topography does not correlate well with with the visceral position in women with pelvic organ prolapse. Int Urogynecol J 1997;8:3369.

35. Dietz HP, Clarke B, Herbison P. Bladder neck mobility and urethral closure pressure as predictors of genuine stress incontinence. Int Urogynecol J Pelvic Floor Dysfunct 2002;13:289-93.

36. Weil A, Gianoni A, Rottenberg RD, Krauer F. The risk of postoperative urinary incontinence after sugical treatment of genital prolapse. Int Urogynecol J 1993;4:74-9.

37. Karram MM. What is the optimal anti-incontinence procedure with advanced prolapse and potential stress incontinence. Int Urogynecol J 1999;10:1-2.

38. Borstad E, Rud T. The risk of developing urinary stress incontinence after avginal repair in continent women. Acta Onstet Gynecol Scand 1989;68:545-9.

39. Weber AM, Walters MD. Cost-effectiveness of urodynamic testing before surgery for women with pelvic organ prolapse and stress urinary incontinence. Am J Obstet Gynecol 2000;183:1338-47.

40. da Silva GM, Gurland B, Sleemi A, Levy G. Posterior vaginal wall prolapse does not correlate with fecal symptoms or objective measures of anorectal function. Am J Obstet Gynecol 2006;195:1742-7.

41. Mouritsen L. Sex and urogynecological 
problems-a survey. Nord Sexology 1997;15:89-98.

42. Tununguntla HSGR, Gousse AE. Female sexual dysfunction following vaginal surgery: myth or reality? Curr Urol Report 2004:5:403-11.

43. Leiblum S, Bachman G, Kemmann E. Vaginal atrophy in the postmenopausal woman. JAMA 1983;249:2195-8.

44. Rogers GR, Villarearl A, Kammerer-Doak D, Qualls C. Sexual function in women with and without urinary incontinence and/or pelvic organ prolapse. Int Urogynecol $\mathrm{J}$ 2001;12:361-5.

45. Handa VL, Harvey L, Cundiff GW, et al. Sexual function among women with urinary incontinence and pelvic organ prolapse. Am J Obstet Gynecol 2004;191:751-6.

46. Rogers RG, Kammerer-Doak D, Darrow A, et al. Sexual function after surgery for stress urinary incontinence and/or pelvic organ prolapse. A multicenter prospective study. Am J Obstet Gynecol 2004;191: 206-10.

47. Silva WA, Kleeman S, Segal J, et al. Effects of a full bladder and patient positioning on pelvic organ prolapse assessment. Obstet Gynecol 2004;104:37-41.

48. Hoyte L, Jakab M, Warfield SK, et al. Levator ani thickness variations in symptomatic and asymptomatic women using magnetic resonance-based 3-dimensional color mapping. Am J Obstet Gynecol 2004;191:856-61.

49. Barber MD, Walters MD, Bump RC. Short forms of two condition- specific quality-oflife questionnaires for women with pelvic floor disorders (PFDI-20 and PFIQ-7). Am J Obstet Gynecol 2005;193:103-13.

50. Brubaker L, Heit MH. Radiology of the pelvic floor. Clin Obstet Gynecol 1993;36:952-9.

51. Schafer, Anck P, Furst G. Anatomy of the anal sphincters: comparison of anal endosonography to magnetic resonance imaging. Dis Colon Rectum 1994;37:777-81.

52. Gantke B, Schafer A, Enck P. Sonographic, manometric, and myographic evaluation of the anal sphincters morphology and function. Dis Colon Rectum 1993;36:1037-41.

53. Sentovich SM, Wong WD, Blatchfent GJ. Accuracy and reliability of transanal ultrasound for anterior anal sphincter injury. Dis Colon Rectum 1998;41:1000-4.

54. Nielsen MB, Rasmussen 00, Pedersen JF. Anal endosonographic findings in patients with obstructed defecation. Acta Radiol 1993;34:35-42.

55. Weidner AC, Low VHS. Imaging studies of the pelvic floor. Obstet Gynecol Clin North Am 1998;25:825-48.

56. Kelvin FM, Maglinte DDT, Hornback JA, Benson JT. Pelvic prolapse: assessment with evacuation proctography (defacography). Radiology 1992;184:547-51.

57. Fielding JR, Dumanli H, Schreyer AG, et al. MR-based three dimensional modeling of the normal pelvic floor in women: quantification of muscle mass. AJR Am J Roentgenol 2000;174:657-60.

58. Yang A, Mostwin, JL, Rosenshein NB. Pelvic floor descent in women: dynamic evaluation with fast MR imaging and cinematic display. Radiology 1991;179:25-33.

59. Poma PA. Nonsurgical management of genital prolapse: a review and recommendations for clinical practice. J Reprod Med 2000;45:789-97.

60. Bump RC, Norton PA. Epidemiology and natural history of pelvic floor dysfunction. Obstet Gynecol Clin North Am 1998;25:72346.

61. Davilla GW, Bernier F. Multimodality pelvic physiotherapy treatment of urinary incontinence in adult women. Int Urogynecol $\mathrm{J}$ 1995;6:187-94.

62. Thakar R, Stanton S. Management of genital prolapse. BMJ 2004;324:1258-62.

63. Davilla GW. Vaginal prolapse management with nonsurgical techniques. Postgrad Med 1996;99:171185.

64. Mimura T, Roy AJ, Storrie JB, et al. Treatment of impaired defecation associated with rectocele by behavioral retraining (biofeedback). Dis Colon Rectum 2000;43:1267-72.

65. Clemons J, Aguilar VC, Tillinghast TA, et al. Patient satisfaction and changes in prolapse and urinary symptoms in women who were fitted successfully with a pessary for pelvic organ prolapse. Am J Obstet Gynecol 2004;190:1025-9.

66. Brincat C, Kenton K, Fitzgerald MP, et al. Sexual activity predicts continued pessary use. Am J Obstet Gynecol 2004;191:198-200.

67. Adams E, Thomson A, Maher C, et al. Mechanical devices for pelvic organ prolapse in omen. Cochrane Database Syst Rev 2004;2:CD004010.

68. Harris TA, Bent AE. Genital prolapse with and without urinary incontinence. J Reprod Med 1990;35:792-8.

69. Meinhardt W, Schuitemaker NEW, Smeets MJGH, et al. Bilateral hydronephrosis with urosepsis due to neglected pessary. Scand J Urol Nephrol 1993;27:419-20.

70. Ott R, Richter H, Behr J, et al. Small bowel prolapse and incarceration caused by a vaginal ring pessary. Br J Surg 1993;80:1157-9.

71. Sze EH, Karram MM. Transvaginal repair of vault prolapse: a review. Obstet Gynecol 1997;89:466-75.

72. Carey MP, Dwyer PL. Genital prolapse: vaginal versus abdominal route of repair. Curr Opin Obstet Gynecol 2001;13:499-505.

73. Brubaker L, Bump R, Jacquetin B, et al. Pelvic organ prolapse. In: Abrams P, Cardozo L, Khoury S, Wein A, editors. Incontinence. 2nd International Consultation on Incontinence. 2nd ed. Plymouth (UK): Plymouth Distributors; 2002. pp. 243-265.
74. Weber AM, Walters MD, Piedmonte MR, Ballard LA. Anterior colporrhaphy: a randomized trial of three surgical techniques. Am J Obstet Gynecol 2001;185:1299-306.

75. Sand PK, Koduri A, Lobel RW, et al. Prospective randomized trial of polyglactin 910 mesh to prevent recurrence of cystoceles and rectoceles. Am J Obstet Gynecol 2001;184:1357-64.

76. Paraiso MF, Weber AM, Walters MD, et al. Anatomic and functional outcome after posterior colporrhaphy. J Pelv Surg 2001; 7:3359.

77. Cundiff GW, Weidner AC, Visco AG, et al. An anatomic and functional assessment of the discrete defect rectocele repair. Am J Obstet Gynecol 1998;179:1451-7.

78. Abrams P, Cardozo L, Fall M, et al. Standardisation Sub-Committee of the International Continence Society. The standardisation of terminology of lower urinary tract function: Report from the standardization sub-committee of the International Continence Society. Neurourol Urodyn 2002;21:167-8.

79. Baden WF, Walker TA, Lindsey JH. The vaginal profile. Tex Med 1968;64:56-8.

80. Marchionni M, Bracco GL, Checcucci V, et al. True incidence of vaginal vault prolapse. Thirteen years experience. J Reprod Med 1999;44:679-84.

81. Cruikshank SH, Kovac SR. Randomized comparison of three surgical methods used at the time of vaginal hysterectomy to prevent posterior enterocele. Am J Obstet Gynecol 1999;180:859-65.

82. McCall ML. Posterior culdoplasty; surgical correction of enterocele during vaginal hysterectomy: a preliminary report. Obstet Gynecol 1957;10:595-602.

83. Wall LL. A technique for modified McCall culdeplasty at the time of abdominal hysterectomy. J Am Coll Surg 1994;178:507-9.

84. Ostrzenski A. A new, simplified posterior culdoplasty and vaginal vault suspension during abdominal hysterectomy. Int $\mathrm{J}$ Gynaecol Obstet 1995;49:25-34.

85. Cruikshank SH. Preventing posthysterectomy vaginal vault prolapse and enterocele during vaginal hysterectomy. Am J Obstet Gynecol 1987;155:1433-40.

86. Maher CF, Qatawneh AM, Dwyer PL, et al. Abdominal sacral colpopexy or vaginal sacrospinous colpopexy for vaginal vault prolapse: a prospective randomized study. Am J Obstet Gynecol 2004;190:20-6. 